\title{
O PAPEL DO GESTOR ESCOLAR NA EDUCAÇÃO INFANTIL
}

\author{
Susimara Santade
}

Discente do Mestrado em Educação da UNOESTE. E-mail: susisantade@uol.com.br

\section{RESUMO}

O texto baseia-se numa pesquisa bibliográfica que teve for objetivo a análise e reflexão sobre o papel do gestor. Ter uma visão global da instituição focando na aprendizagem dos alunos é um dos principais atributos de quem assume a direção de uma escola, tendo ou não experiência em gestão escolar. Ao gestor é creditada grande parte dos sucessos e/ou fracassos de uma instituição. Ele é o responsável legal da instituição e, espera-se que promova condições necessárias à aprendizagem com adequação dos espaços, cuidando também da administração dos recursos financeiros e melhorando as relações interpessoais entre funcionários, professores e a comunidade. O termo gestor só passou a ser usado em meados dos anos 1980, visando levar aos sistemas públicos educacionais a perceberem a importância desse profissional no sistema de ensino e também a formar colegiados para participar da gestão participativa. Quanto a gestão democrática, ela exige a compreensão em profundidade dos problemas postos pela pratica pedagógica. Em relação ao projeto político-pedagógico é a própria organização do trabalho pedagógico da escola. Essa construção parte dos princípios de igualdade, qualidade, liberdade, gestão democrática e valorização do magistério. A tarefa dos gestor não é fácil, pois ele é o educador, o administrador, a cabeça pensante em todos os âmbitos e espaços, o observador com visão de mediar a aprendizagem tornando-a mais significativa; capacitar seus professores, motivando-os a alcançarem seus objetivos numa formação contínua, sempre idealizando sonhos para que a escola cresça, trabalhando com metas, trilhando caminhos a serem percorridos.

Palavras-chave: Educação Infantil, Gestão educacional, Políticas públicas, Gestão democrática, Gestão participativa

\section{INTRODUÇÃO}

De minha experiência na educação do Estado de São Paulo, tanto como docente e gestora, surgiu o desejo de informar e até mesmo conscientizar os próprios gestores da importância e da responsabilidade que a função exige, função esta que não se restringe apenas à gestão do Ensino Fundamental I e II e Ensino Médio, mas também na Educação Infantil.

\section{O PAPEL DO GESTOR ESCOLAR NA EDUCAÇÃO INFANTIL}

Antes de um maior aprofundamento no universo da educação infantil, se faz discorrer sobre precedentes históricos, pelo âmbito da política pública, gestão democrática e gestão pedagógica, com a finalidade de melhor prepararmos para a árdua tarefa de esboçar sobre este tema. 
No decorrer da década de 1980, com o aprofundamento do processo de democratização política de nossa sociedade, aumentam as pressões para que o diretor revele sua face de educador. Segundo Nogueira (1995), a própria palavra "Diretor" começa a ser questionada. Ganha força a proposta de que a direção da Escola seja exercida não por um único indivíduo, mas por um colegiado, formado por representantes de todos os envolvidos no processo educativo. Argumenta a autora que com as eleições de 1982, chegam ao poder, nos executivos estaduais e municipais, administrações progressistas que passam a estimular a eleição, em todas as escolas, de Conselhos Consultivos ou mesmo Deliberativos. Por meio de seus representantes nesses Conselhos, pais, alunos, funcionários e professores são chamados a participar das decisões sobre temas políticos pedagógicos, administrativos e financeiros. Os Conselhos devem também acompanhar a implementação dessas decisões e avaliar a eficiência e eficácia das ações desenvolvidas na escola.

Entretanto, esclarece a autora que:

Tudo isso é muito difícil, pois a nossa sociedade caracteriza-se pela falta de experiência, de participação, pelo descrédito as instituições representativas e pelo predomínio do individualismo, desestimulando a busca de soluções coletivas para os problemas da realidade. (NOGUEIRA, 1995, p.59).

Assim, os Conselhos de Escola estão ainda longe de serem um espaço onde toda a comunidade escolar possa autogerenciar-se, diagnosticando e encaminhando soluções.

$\mathrm{Na}$ opinião da autora, existe uma resistência em muitas escolas públicas de educação básica contra essa iniciativa. Muitos pais, alunos não se encontram preparados para a iniciativa do que se pode chamar de gestão participativa. Mesmo entre os funcionários e professores não se consideram preparados, além do que, o diretor não está abrindo mão de sua liderança para exercitá-la democraticamente, num processo de educação política em que todos os envolvidos crescem como cidadãos.

O gestor deve ser capaz de contribuir para formar na escola uma gestão coletiva sendo mais um articulador com os demais participantes do processo educativo.

\section{1- Novos Padrões de Gestão Educacional.}

A revalorização da gestão educacional, ou escolar, nos documentos da política dos anos 90, promoveu a emergência dos estudos na área, entretanto, isto não produz um conhecimento propriamente dito. 
Segundo Machado (1998, p.18), "a literatura oficial promove um movimento de síntese por vezes de retrocesso, pelo resgate maquiado das escolas de pensamentos anteriores com forte componente de técnicas de controle".

No entender da autora, as transformações sociais, em especial as decorrentes do crescimento econômico excludente, com ênfase na evolução tecnológica têm provocado mudanças profundas nos mercados de trabalho em todo mundo. Entre as prioridades está o atender a crescente demanda por parte das economias de trabalhadores adaptáveis capazes de adquirir novos conhecimentos sem dificuldade e deve contribuir a constante expansão do saber.

Segundo Libâneo (2001) a tarefa dos gestores educacionais visa dirigir e coordenar o andamento dos trabalhos, o clima do trabalho, a eficácia na utilização dos recursos e os meios, em função dos objetivos da escola.

O movimento da gestão em educação reconhece a necessidade de unir algumas mudanças estruturais e de procedimentos que, de acordo com Luck (2000) são os seguintes: a) participação da comunidade escolar na seleção dos diretores da escola; b) criação de um colegiado/ Conselho Escola que tenha tanto autoridade deliberativa quanto poder decisório; c) repasse de recursos financeiros as escolas e conseqüentemente aumento de sua autonomia.

Afirma, a autora, que no Brasil alguns Estados tem avançado no sentido de combinar o mapeamento de candidatos potenciais para a função de diretor com base em critérios profissionais, com a definição de uma lista contendo o nome de três candidatos qualificados que se submetem a uma eleição durante uma assembléia escolar que define, por meio de votos de pais, mestres, alunos e demais funcionários, o futuro diretor. "Este avanço combina a competência profissional do candidato com uma forte participação da comunidade e de todos os funcionários e professores da escola". (LÜCK, 2000, p.94).

\section{2- Gestão Democrática na Escola Pública}

A gestão democrática é um princípio consagrado na Constituição (1988) vigente e abrange dimensões pedagógicas, administrativas e financeiras, afirma Demo (1994). Ela exige uma ruptura histórica na prática administrativa da escola, com o enfrentamento das questões de exclusão e reprovação e da não permanência do aluno na sala de aula, o que vem provocando a marginalização das classes populares.

A gestão democrática exige a compreensão em profundidade dos problemas postos pela pratica pedagógica. Ela visa romper com a separação entre concepção e execução, entre o pensar 
e o fazer, entre a teoria e a prática. Busca resgatar o controle do processo e do produto do trabalho pelos educadores.

A gestão democrática implica principalmente o repensar da estrutura de poder da escola, tendo em vista sua socialização. A socialização do poder propicia a prática da participação coletiva, que atenua o individualismo; da reciprocidade, que elimina a exploração e da autonomia que anula a dependência de órgãos intermediários que elaboram políticas educacionais das quais a escola é mera executora. (DEMO, 1994, p.21).

A busca da gestão democrática inclui, necessariamente, a ampla participação dos representantes dos diferentes segmentos da escola nas decisões/ações administrativa pedagógicas ali desenvolvidas.

Neste sentido, fica claro entender que a gestão democrática, no interior da escola, não é um princípio fácil de ser consolidado, pois se trata da participação critica na construção do projeto político-pedagógico e na sua gestão.

A gestão democrática é uma maneira diferente de fazer educação, pois tem um estilo de administração participativa que envolve todos os escolares no processo de busca da mudança da escola. Essa mudança que se pretende envolve a autonomia na organização educacional na gestão administrativa e a livre organização dos segmentos nos processos decisórios em órgãos colegiados.

Na gestão democrática o processo de descentralização é concretizado na medida em que a escola vai construindo a sua autonomia. Com a autonomia, a escola torna-se o centro das decisões responsabilizando-se por elas. Para Rios (1982, p.77), "a escola tem uma autonomia relativa e a liberdade é algo que se experimenta em situação e esta é uma articulação de limites e possibilidades".

\section{3- Gestão e Construção do Projeto Político-Pedagógico.}

O projeto político-pedagógico é entendido como a própria organização do trabalho pedagógico da escola. A construção do projeto político- pedagógico da escola. Essa construção parte dos princípios de igualdade, qualidade, liberdade, gestão democrática e valorização do magistério. A escola é concebida como espaço social marcado pela manifestação de práticas contraditórias, que apontam para a luta e/ou acomodação de todos os envolvidos na organização do trabalho pedagógico. 
Enfatiza Rios (1982) que se deve analisar e compreendera organização do trabalho pedagógico no sentido de gestar uma nova organização que reduza os efeitos de sua fragmentação e do controle hierárquico.

“Nessa perspectiva, a construção do projeto político- pedagógico é um instrumento de luta, é uma forma de contrapor-se e fragmentação do trabalho pedagógico e sua rotinização, a dependência e aos efeitos negativos do poder autoritário e centralizador dos órgãos da administração central". (RIOS, 1982, p.79).

Na construção do projeto político-pedagógico da escola, os educadores se deparam com uma multiplicidade de termos ora utilizados de maneira diferenciada, tais como: projeto de escola, plano escolar, plano diretor, plano de currículo, proposta pedagógica, projeto político pedagógico, etc.

Para Machado (1997, p.96) "a palavra projeto costuma ser associada ao trabalho do arquiteto ou do engenheiro quanto aos trabalhos acadêmicos ou aos planos de ação educacional, política ou econômica (apud LÜCK, 2000)".

\section{4- Gestão e Escola Participativa.}

A partir da segunda metade da década de noventa, mais especificamente com a promulgação da nova Lei de Diretrizes e Bases da Educação Nacional, Lei 9394/96, o Estado de São Paulo, por meio da Secretaria da Educação promoveu algumas mudanças que priorizaram a gestão participativa da educação, tais como: a) reorientação da natureza da qualidade das intervenções; b) articulação e integração de um projeto de política educacional; c) integração dos aspectos humanos, físicos e materiais; d) estabelecimento de parcerias com vistas a revolucionar a produtividade dos recursos públicos.

De acordo com Libâneo (2001), isto significa que o Estado passou de mero gestor de uma máquina gigantesca para de articulador e integrador de um projeto de Educação, para a formulação de uma política educacional que integrasse os mais diferentes aspectos, desde os recursos humanos, físicos e materiais até o estabelecimento de parcerias com todas agências responsáveis pela educação escolar.

Segundo Luck (2000), a participação deve ser entendida como um processo de aprendizagem que requer: espaços sociais específicos para sua concretização; tempo para as idéias sejam debatidas e analisadas. Mas, essa mudança não ocorre do dia para noite e, por isso 
requer esforço de todos aqueles preocupados com a formação do cidadão e de uma escola participativa.

\section{5- O diretor de Pré-Escola / Educação Infantil e a qualidade do ensino.}

O funcionamento da Escola de Educação Infantil e a qualidade dos seus serviços, bem como de qualquer organização dependem do trabalho que cada pessoa realiza no seu interior. As atividades desenvolvidas são intercomplementares e, no conjunto, garantem as condições de funcionamento da Escola. Por isso nunca é demais destacar a importância do trabalho de cada um, bem como do seu conjunto e do diretor em particular.

Segundo Huet, Fares e Benedetti (coords) (1992, p.16)

"uma escola sem o diretor seria o mesmo que supor como um organismo regido por leis naturais, que prescinde da vontade e da intenção da pessoa humana".

Segundo as autoras, no que se refere ao trabalho do diretor junto aos professores, um comportamento totalmente autoritário cria uma enorme confusão de papéis, significando na pratica, uma interferência indevida numa área de não é o trabalho docente.

O autoritarismo confunde papéis tanto quanto o seu oposto, o espontaneismo em que cada professor decide o que faz e como faz. Em nenhum dos casos a escola irá bem.

É preciso ter claro que todo e qualquer organização existe com uma finalidade e cumpre uma função social, econômica ou cultural em relação ao meio ao qual faz parte.

Os debates mais amplos sobre esta questão e os pontos de vista expressos pelos diretores levaram os estudiosos do assunto a alguns entendimentos básicos que, segundo Huet, et al (1992) são os seguintes:

Em primeiro lugar, a Educação Infantil desempenha uma função social. Ela abriga e alimenta proporções significativas de crianças de zero a seis anos de idade, ou de zero aos cinco anos, dependendo do Estado ou do Município, constituindo importante espaço de socialização além das fronteiras da família. Em segundo lugar, ao abrigar e cuidar das crianças, liberta a mulher/mãe da função guardiã - facilita sua inserção no mercado de trabalho. Ela cumpre, portanto um papel importante na redefinição do papel social da mulher na sociedade atual. (HUET, 1992, p.17).

Em terceiro lugar a Pré-Escola e/ou Educação Infantil tem uma função pedagógica que consiste em promover o desenvolvimento da criança própria a sua idade e o diretor deve 
entender com a profundidade em que consiste esta função pedagógica que amplia em desenvolver na criança o conhecimento do mundo físico, social e de si mesma e, ampliar a sua capacidade de comunicação e expressão. Esta capacidade implica, entre outras coisas, o domínio dos códigos da linguagem escrita que é a alfabetização, no sentido estrito.

As autoras concluem que "um diretor de Pré - Escola poderá ser um excelente administrador sem jamais ser um administrador da Educação se não tiver claro estes aspectos e se não conhecer a função precípua dessa unidade escolar". (ibidem, p.18).

Além disso, as autoras acrescentam que o diretor deve conhecer a criança em idade pré escolar o que requer do educador um agudo senso de observação, uma atenção constante a detalhes de comportamento com a preocupação de identificar o que lhe é peculiar.

Para o educador (professores, direto) que lida com crianças na idade pré-escolar, as pesquisas já acumularam conhecimentos preciosos, imprescindíveis a estes profissionais, os quais sejam: a) como as crianças elaboram e constroem conhecimentos; b) como aprendem; c) como aprendem o mundo físico e social, enfim, o meio em que vivem; d) como vêem o mundo criado pelos adultos: padrões de relacionamento, papéis sociais, etc.

Sem esses conhecimentos e essas preocupações não é possível construir uma Pré-Escola que traga uma contribuição efetiva para o desenvolvimento da criança. É possível afirmar que é dever do diretor/gestor/educador, conhecer a criança neste sentido para atuar proporcionando um ensino significativo e de qualidade, que proporcione as crianças o acesso ao conhecimento e a construção da cidadania.

\section{CONSIDERAÇÕES FINAIS}

As várias modalidades de gestão exigem um estudo e aprofundamento dos conceitos e leis que as compõem, pois se trata de uma ampla abrangência sobre todas as funções do "cargo" de gestor.

Existe uma preocupação grande de quem deverá assumir o cargo de gestor nas diferentes instâncias e modalidades de ensino, principalmente na educação infantil, pois não é somente na formação da criança que este profissional deverá estar atuando, mas também na formação e capacitação dos docentes que integram o grupo.

É imprescindível políticas adequadas para que se tenha uma educação de qualidade e com comprometimento. 


\section{REFERÊNCIAS}

AMARAL, Patrícia, P. Experiências Musicais. Aprendizagem de canções ajuda a desenvolver o processo criativo. Revista do Professor, Porto Alegre, 15 (59): 5-7, julho/set, 1999.

BRASIL. Referencial Curricular para a Educação Infantil. Ministério da Educação e do Desporto. Secretaria de Educação Fundamental. Brasília: MEC/SEF, 1998 V.3 - pp 45 - 74.

DEMO, Pedro. Educação e Qualidade. Campinas SP: Papirus, 1994

HUET, Bernard Fares, Jacyra; Benetti, Maria Luiza C. (coordenadoras). Experiências de desenvolvimento na área do ensino pré - escolar. IDEAIS. São Paulo: FDE, 1992.

JEANDOT, N. Explorando o universo da música. São Paulo. Scipione, 2001.

LIBÂNEO, José Carlos. Organização e Gestão Escolar. Teoria e Prática: Goiânia: Alternativa, 2001.

LÜCK, Eloísa et al. A Escola Participativa: o trabalho do gestor escolar. 4 ed. Rio de Janeiro: DP\&A, 2000.

MACHADO, Lourdes Marcelino. Novos Padrões de Gestão Educacional: a lógica do mercado e a lógica do direito a educação. Tese de Livre Docente, agosto, 2001.

SÃO PAULO (Estado) Secretaria da Educação. Coordenadoria de Estudos e Normas Pedagógicas. Proposta Curricular para a Educação Pré - Escolar. 2 ed. São Paulo: SE/CENP, 1999, p.30 - 31. 